\title{
Double Torsion testing of thin porous zirconia supports for energy applications: toughness and slow crack growth assessment
}

\author{
Published in Journal of the European Ceramic Society 40 [8] (2020) pp. 3191-3199 \\ https://doi.org/10.1016/j.jeurceramsoc.2020.02.019
}

Peyman Khajavi ${ }^{1}$,* Jérôme Chevalier ${ }^{2}$, Peter Vang Hendriksen ${ }^{1}$, Joe W. Tavacoli ${ }^{1}$, Laurent Gremillard $^{2}$, Henrik Lund Frandsen ${ }^{1}$

1. Department of Energy Conversion and Storage, Technical University of Denmark, Fysikvej, 2800 Kgs. Lyngby, Denmark

2. Univ Lyon, INSA-Lyon, CNRS, MATEIS UMR 5510, F-69621 Villeurbanne, France

* Corresponding author: pkha@dtu.dk

\begin{abstract}
Thin, porous zirconia-based ceramic components are of high interest in energy application devices where they are used as structural ceramics. Mechanical reliability of such devices is not only dependent on the fracture toughness of the ceramic components, but also on their sensitivity to slow crack growth (SCG). In this work, the fracture toughness and SCG behavior of porous (4.5 to $45.5 \%$ ) and thin $(\sim 0.25 \mathrm{~mm}) 3 \mathrm{Y}$-TZP ceramics are investigated using the Double Torsion method. The analysis of the double torsion data, previously developed for dense materials, was here assessed and adapted. The compliance of the samples was observed to change linearly with crack length and the measured stress intensity factor was dependent on crack length, as for dense materials. This dependency decreased by increasing the sample porosity. For all materials, the ratio of the SCG threshold to fracture toughness was of $0.56 \pm 0.06$.
\end{abstract}

\section{Keywords:}

Slow crack growth, Porosity, Double torsion, Solid oxide cells, Energy applications 


\section{Introduction}

Ceramics are brittle materials: they fail before plasticity, at low strains and they are sensitive to the presence of defects. Such brittleness needs careful attention when a porous ceramic component with low thickness is desired, as it is the case with thin ceramic membranes and in solid oxide fuel and electrolysis cells (SOCs) [1-3]. Zirconia is one of the most interesting materials in this context due to its excellent combination of fracture toughness and strength [4]. In addition to its use in dense structures, zirconia and zirconia-toughened materials are thus promising alternatives for use in thin porous components, where a material with high crack resistance is required.

Crack resistance is often described in terms of fracture toughness, $K_{I C}$, which represents the critical stress intensity factor at which fast fracture occurs. Nevertheless, the mechanical reliability of zirconia like many other oxide ceramics is affected by the Slow (also referred to as Subcritical) Crack Growth (SCG), which represents slow-crack propagation at stress intensity factors below the critical value for fast fracture $\left(K_{I C}\right)$. This influences the long-term reliability and lifetime of the ceramic, since it may cause delayed failure. Fortunately, there is a threshold stress intensity factor, $K_{I O}$, below which the crack propagation rate tends to zero [5,6]. Hence, judicious material selection for a given application requires evaluation of $K_{I 0}$ alongside $K_{I C}$. For SOCs the stresses are to a high degree determined by thermal gradients, which are sustained over thousands of hours, making $K_{I 0}$ highly relevant [7].

SCG is especially promoted in water-containing environments, due to the interaction of water molecules with cracks surfaces. This process has been studied in different environments containing water molecules, such as humid air, water and body fluid. The studies have focused mostly on dense systems [8-12]. The measured threshold intensity factor has been reported to be considerably lower than the fracture toughness. For example, De Aza and co-workers [8] measured the fracture threshold of dense 3 Y-TZP as approximately $44 \%$ lower than its fracture toughness. In other words, crack propagation can occur at stress intensity factors of $56 \%$ of the toughness in such ceramics, which shows the importance of having the full picture of the crack rate, $V$, versus applied stress intensity factor, $K_{I}$ ( $V$ - $K_{I}$ curves), including $K_{I O}$. The susceptibility to SCG is also of great importance in porous zirconia ceramics. Boccaccini and co-workers [13] studied the mechanical properties of porous 3 YSZ ceramics and observed the threshold intensity factor of 49 and $54 \%$ porous samples to be approximately 45 and $52 \%$ lower than their fracture toughness, respectively. Radovic and co-workers [14] investigated the SCG behavior of porous Ni-8YSZ samples. The authors reported a decrease of the threshold intensity factor with porosity and temperature.

For most oxide ceramics in their dense form, including zirconia and zirconia-toughened ceramics, the $V-K_{I}$ curves observed in air typically consist of three distinct stages and the threshold value $\left(K_{I 0}\right)[5,15]$, as schematically shown with the curve $a$ in Figure 1.

The first stage (stage I) corresponds to a regime where the rate of crack propagation is limited by the reaction rate between corrosive molecules (e.g. water) and atomic bonds at the crack tip. In the second stage (stage II), the crack growth is controlled by the transport rate of the corrosive molecules and in the third stage (stage III) higher ranges of crack velocities are witnessed, where the crack propagation is relatively independent of the corrosive environment $[15,16]$.

In each stage, the relation between the crack velocity, $V$, and stress intensity factor, $K_{I}$, can be represented by a power law:

$$
V=A K_{I}^{n}
$$

where $A$ and $n$ are slow crack growth parameters. 
The values of $A, n$ and $K_{I 0}$ depend not only on the material but also on the type and concentration of corrosive agents and the temperature. The variation of these factors can lead to changes in the $V$ $K_{I}$ curves. For instance, for zirconia and zirconia-toughened ceramics it has been shown that increasing the concentration of water molecules and the temperature shift the first and second stages to higher crack velocities [11], as schematically illustrated in Figure 1. For crack propagation in water (curve d), only one stage is observed as the crack rate is no longer limited by the diffusion rate of water molecules from the crack mouth to the crack tip.

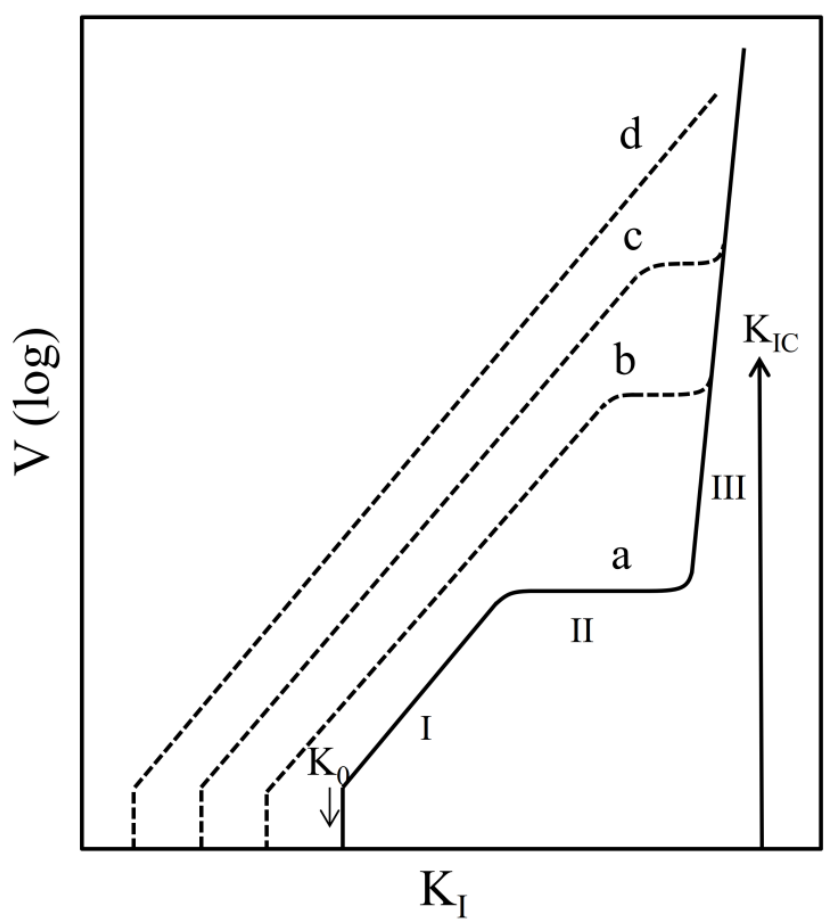

Figure 1: Typical crack velocity versus stress intensity factor (V-KI) curves observed in (a) air and (d) water. Increasing humidity and temperature of the environment will shift the first and second stages to higher crack velocities as schematically shown by curves $(a)$ to $(d)$.

Double torsion is a simple yet powerful method to measure fracture toughness and study the slow crack growth behavior of brittle ceramics. Using the double torsion method, the $V$ - $K_{I}$ diagrams can readily be obtained through load relaxation experiments. Analytical analysis of double torsion specimens indicates that the stress intensity factor is independent of crack length $[17,18]$. However, it has been shown that for an accurate determination of stress intensity factor, crack length needs to be considered [19-22]. Different corrections are thus suggested to obtain a more accurate evaluation of the stress intensity factor, $K_{I}$. Chevalier and co-workers [20] showed experimentally that the stress intensity factor is dependent on the crack length with the following equation:

$$
K_{I}=K_{I(\text { analytical })}\left(\frac{a}{a_{0}}\right)^{\gamma}
$$

where $K_{I(\text { analytical })}$ is derived from an analytical solution (introduced in the experimental section), and $a_{0}$ and $a$ are the notch and crack length, respectively. The $\gamma$ value for a $2 \mathrm{~mm}$ thick 3Y-TZP sample was found experimentally to be 0.18 [20]. Using a three dimensional finite element analysis 
(FEA), Ciccotti and co-workers [23,24] concluded that crack length and geometrical parameters should also be considered in the calculation of stress intensity factor. This was mainly attributed to the non-linear compliance to crack length relationship. A similar conclusion is also drawn by Becker and co-workers [25]. Application of these corrections has also been considered in later studies. Becker and co-workers [25] showed that the Chevalier's correction overestimates the stress intensity factor, while it is underestimated when employing the Ciccotti's correction. Madjoubi and co-workers [26] reported that applicability of the analytical model, the corrected model by Chevalier and Ciccotti are all restricted to specific geometries and a general correction cannot be applied. The aforementioned studies highlight the importance of the samples geometry to the dependency of stress intensity factor on the crack length and indicate that the evolution of $K_{I}$ versus crack length should be assessed for any new sample geometry.

In this work, the applicability of the double torsion technique to study the slow crack growth behavior of thin porous zirconia samples was thus assessed, since this, to the best of authors' knowledge, has not been reported before. The study was performed on three mol\% yttria stabilized zirconia (3Y-TZP), as it is one of the most studied tetragonal zirconia ceramics - being material of interest for porous support in asymmetric ceramic membranes and the support layer of solid oxide fuel and electrolysis cells $[1,13,27]$. SCG behavior of porous samples, ranging from 4.5 to $45.5 \%$ porosity with thickness of ca. $0.25 \mathrm{~mm}$ was then investigated, as zirconia ceramics used for such applications are not dense. Variation of fracture toughness and threshold stress intensity factor with porosity is also reported.

\section{Experimental}

\subsection{Sample preparation}

The samples studied in this work were prepared from commercial $3 \mathrm{~mol} \%$ yttria doped zirconia (3YSZ) powders, (TZ-3Y, TOSOH Corporation) by tape casting [28,29]. The manufactured tapes had a thickness of approx. $300 \mu \mathrm{m}$ after drying, and were cut into different sheets. The green sheets were sintered for $15 \mathrm{~h}$ at different temperatures, i.e. $1060,1200,1300$ and $1340^{\circ} \mathrm{C}$.

The sintered samples were laser cut to the size of $20 \times 34 \mathrm{~mm}^{2}$. On all specimens, a $500 \mu \mathrm{m}$ width notch with a length of $8 \mathrm{~mm}$ was also laser cut. To obtain a sharp notch tip, the last two millimeters were cut with a V-shape. The sample and notch configuration is shown in Figure 2. Some of the samples were also cut to the dimension of $20 \times 40 \mathrm{~mm}^{2}$ (and a $10 \mathrm{~mm}$ long notch). The results of compliance analysis and toughness measurements on the 34 and $40 \mathrm{~mm}$ long samples were completely consistent.

\subsection{Characterization}

The microstructure of the samples was examined using field emission scanning electron microscopy (FE-SEM, Merlin, Carl Zeiss, Germany). The samples were polished and thermally etched at $50^{\circ} \mathrm{C}$ below their corresponding sintering temperature for $0.5 \mathrm{~h}$, with heating and cooling rate of $8{ }^{\circ} \mathrm{C} / \mathrm{min}$, to reveal the microstructure. The sample sintered at $1060^{\circ} \mathrm{C}$ was thermally etched at $1150^{\circ} \mathrm{C}$ as the grain boundaries could not be delineated after etching at $1010^{\circ} \mathrm{C}$. Grain size distribution and average grain size of the samples were estimated by measuring the size of 150 grains in each sample.

The crack lengths of the samples after relaxation tests were evaluated using electron and optical microscopy. Porosity of the specimens was measured considering their mass and geometric 
dimensions and the theoretical density of 3 YSZ $\left(6.05 \mathrm{~g} / \mathrm{cm}^{3}\right)$. X-ray diffraction (XRD, Bruker D8) was used to study the crystalline phase of the sintered samples. The crystalline phase of fractured surfaces after toughness measurement was investigated by Raman spectroscopy (Renishaw InVia spectrometer).

\subsection{Mechanical testing}

The loading configuration of the double torsion test is presented in Figure 2. The $V$ - $K_{I}$ curves were determined by the load relaxation method as first suggested by Williams and Evans [18]. In our experiments, samples were loaded with a displacement rate of $0.6 \mathrm{~mm} / \mathrm{min}$. When the load $(P)$ reached approximately 0.95 of the critical load for failure $\left(P_{I C}\right)$, the crosshead was stopped. Under this constant displacement condition, the load relaxation occurs because of the crack propagation. The load versus time curve was monitored and used for the analysis.

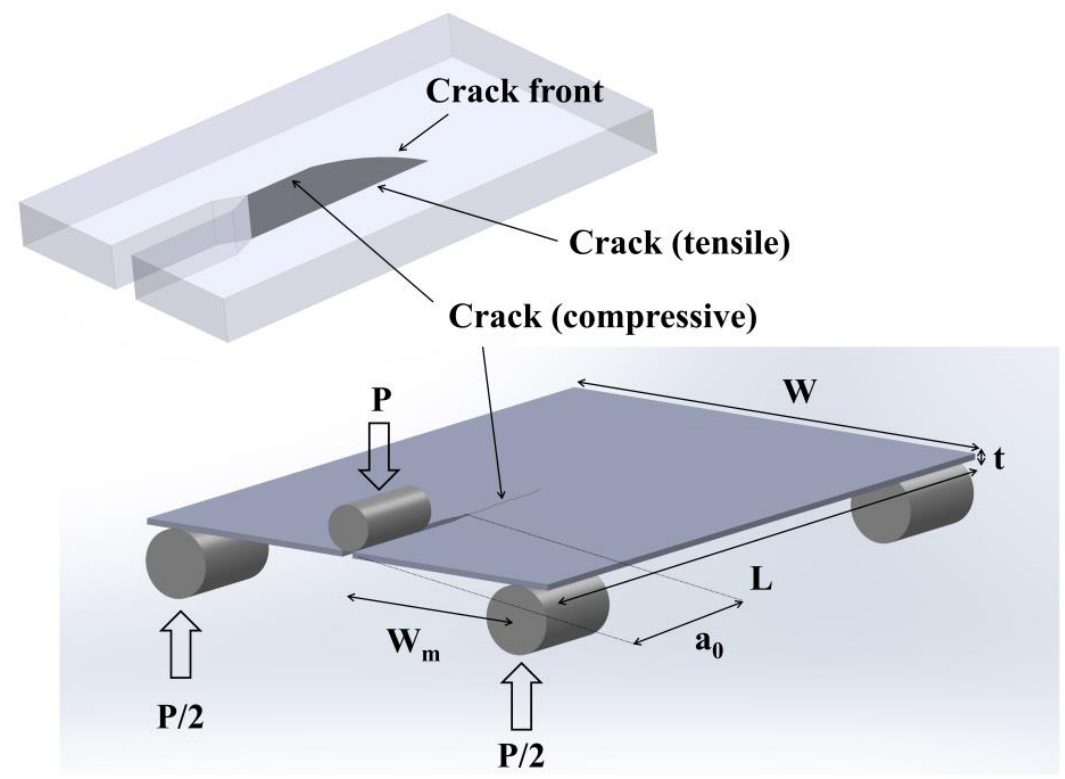

Figure 2: Loading configuration of the double torsion measurement, specimen and notch geometries; the typical curved crack front in double torsion experiments is shown schematically.

The stress intensity factor at the crack tip is first calculated using the analytical equation of the stress intensity factor for the double torsion specimen (without considering its variation with crack length) $[17,18]$ :

$$
K_{I(\text { analytical })}=\frac{P W_{m}}{t^{2}}\left(\frac{3(1+v)}{W \psi(t, W)}\right)^{1 / 2}
$$

where $W_{m}$ is the moment arm, and $W$ and $t$ are the width and thickness of the specimen, respectively. $v$ is the Poisson ratio and $\psi(t, W)$ a thickness correction factor given by [30]:

$$
\psi(t, W)=1-1.2604(t / W)+2.4(t / W) \exp (-W \pi / 2 t)
$$


Eq. 3 gives the stress intensity factor for a plane stress condition assuming that $K_{I}$ is independent of crack length. The applicability of this equation was next assessed experimentally on the specified samples.

The compliance $(C)$ of the double torsion specimen, defined as the ratio of the specimen deflection $(4)$ to the load, was obtained for samples with different porosities from the slope of loaddisplacement curves at different crack lengths.

The initial analysis of double torsion, as proposed by Williams and Evans [18] considers that compliance is a linear function of crack length $(a)$

$$
C=\frac{\Delta}{P}=B a+D
$$

where $B$ and $D$ are constants depending on the material and geometry. Theoretical analysis of the compliance of double torsion specimens gives the following analytical expression for $B$ :

$$
B=\frac{6 W_{m}^{2}(1+v)}{E W t^{3} \psi(t, W)}
$$

where $E$ and $v$ are the Young's modulus and Poisson's ratio, respectively.

To check for linear behavior, compliance versus crack length curves were therefore experimentally obtained for samples with different porosities.

During a load relaxation tests, the crack growth rate, $V$, can be determined using the compliance analysis. If the compliance follows Eq. 5 , the crack velocity at constant displacement $(\Delta=$ const.) can be derived to be

$$
V=\left(\frac{d a}{d t}\right)_{\Delta}=-\frac{P_{i, f}}{P^{2}}\left[a_{i, f}+D /_{B}\right]\left(\frac{d P}{d t}\right)_{\Delta}
$$

In Eq. 7, $P_{i, f}$ and $a_{i, f}$ are the load and crack length, respectively in the initial $(i)$ or final $(f)$ stages, and $t$ refers to time. Use of final values is usually preferred, as the initial crack length might not be accurately determined due to the possible crack propagation at the end of the loading stage before the relaxation experiments [26]. $P$ and $\left(\frac{d P}{d t}\right)_{\Delta}$ are determined from the load-relaxation experiments. Since $P$ and $\left(\frac{d P}{d t}\right)_{\Delta}$ vary with time (as the crack propagates and the compliance changes), both $K_{I}$ (from eq. 3 ) and $V$ also vary with time, thus this method enables plotting $V$ - $K_{I}$ curves.

The fracture toughness of the samples was obtained by performing the tests using a fast displacement rate $\left(6 \mathrm{~mm} / \mathrm{min}\right.$ ) in $\mathrm{N}_{2}$ atmosphere (to avoid the possible SCG effect caused by air humidity), both at room temperature and $800^{\circ} \mathrm{C}$. In addition, the double torsion tests were carried out in ambient environment with a displacement rate of $0.6 \mathrm{~mm} / \mathrm{min}$, and the apparent toughness of the samples under these conditions was determined. 


\section{Results and discussion}

\subsection{Characteristics of the samples}

The porosity, thickness and average grain size of the samples are summarized in Table 1 . The samples are denoted as $3 \mathrm{Y}-\mathrm{TZP}-\mathrm{X}$, where $\mathrm{X}$ represents the average porosity in percentage. The XRD patterns of the samples sintered at different temperatures showed that all the materials are in the tetragonal crystalline form. The grain size distribution of the $3 \mathrm{Y}-\mathrm{TZP}-45.5 \%$ is consistent with the particle size of the starting powder (as reported by the supplier to be around $40 \mathrm{~nm}$ ). This indicates that the sintering process at $1060^{\circ} \mathrm{C}$ is in the initial stage of sintering, before the grain growth [31]. It also assures that the short thermal etching of the $3 \mathrm{Y}-\mathrm{TZP}-45.5 \%$ at $1150^{\circ} \mathrm{C}$ (slightly higher than its sintering temperature) did not cause grain growth.

Table 1: Dimensions, porosity, and grain size of specimens. The numbers in parentheses show the standard deviation.

\begin{tabular}{|c|c|c|c|c|}
\hline Sample name & $\begin{array}{c}\text { Sintering } \\
\text { temperature }\left[{ }^{\circ} \mathrm{C}\right]\end{array}$ & $\begin{array}{c}\text { Porosity } \\
{[\%]}\end{array}$ & $\begin{array}{c}\text { Thickness } \\
{[\mu \mathrm{m}]}\end{array}$ & $\begin{array}{c}\text { Grain size } \\
{[\mathrm{nm}]}\end{array}$ \\
\hline $3 \mathrm{Y}-\mathrm{TZP}-4.5 \%$ & 1340 & $4.5(1)$ & $261(4)$ & $238(84)$ \\
\hline $3 \mathrm{Y}-\mathrm{TZP}-8 \%$ & 1300 & $8(1.5)$ & $262(2)$ & - \\
\hline $3 \mathrm{Y}-\mathrm{TZP}-25 \%$ & 1200 & $25(1)$ & $237(5)$ & $149(34)$ \\
\hline $3 \mathrm{Y}-\mathrm{TZP}-45.5 \%$ & 1060 & $45.5(1)$ & $310(7)$ & $40(10)$ \\
\hline
\end{tabular}

The SEM micrographs of the 3Y-TZP-45.5\%, 3Y-TZP-25\% and 3Y-TZP-4.5\% (Figure 3) show the very small grain size of the sintered materials. A $3 \mathrm{Y}-\mathrm{TZP}$ ceramic with a fine grain microstructure can be considered as a brittle polycrystalline material that will show R-curve behavior only over very small crack lengths $(5-10 \mu \mathrm{m})[32,33]$. Consequently, the effect of the R-curve behavior on the $V-K_{I}$ curves evaluated in this work can be neglected.

Figure $4 \mathrm{a}, \mathrm{b}$ illustrates the notch tip and the crack as propagated from the notch after a load relaxation experiment carried out on $3 \mathrm{Y}-\mathrm{TZP}-25 \%$. The notch radius is approximately $50 \mu \mathrm{m}$. Figure $4 c$ shows the SEM micrograph of the crack tip. 

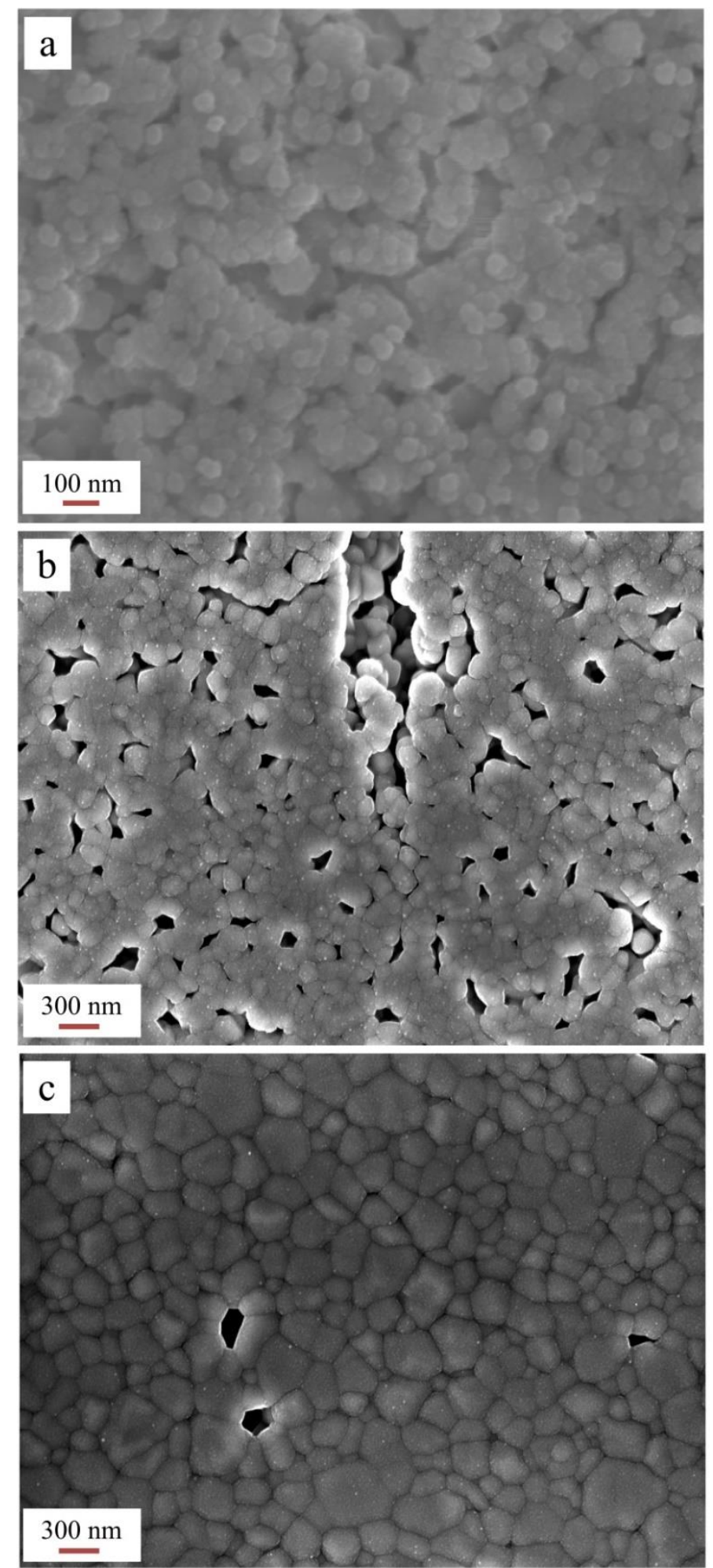

Figure 3: SEM micrographs of the polished and thermally etched samples (a) 3Y-TZP-45.5\%, (b) 3Y-TZP$25 \%$ and $(c) 3 Y-T Z P-4.5 \%$. 

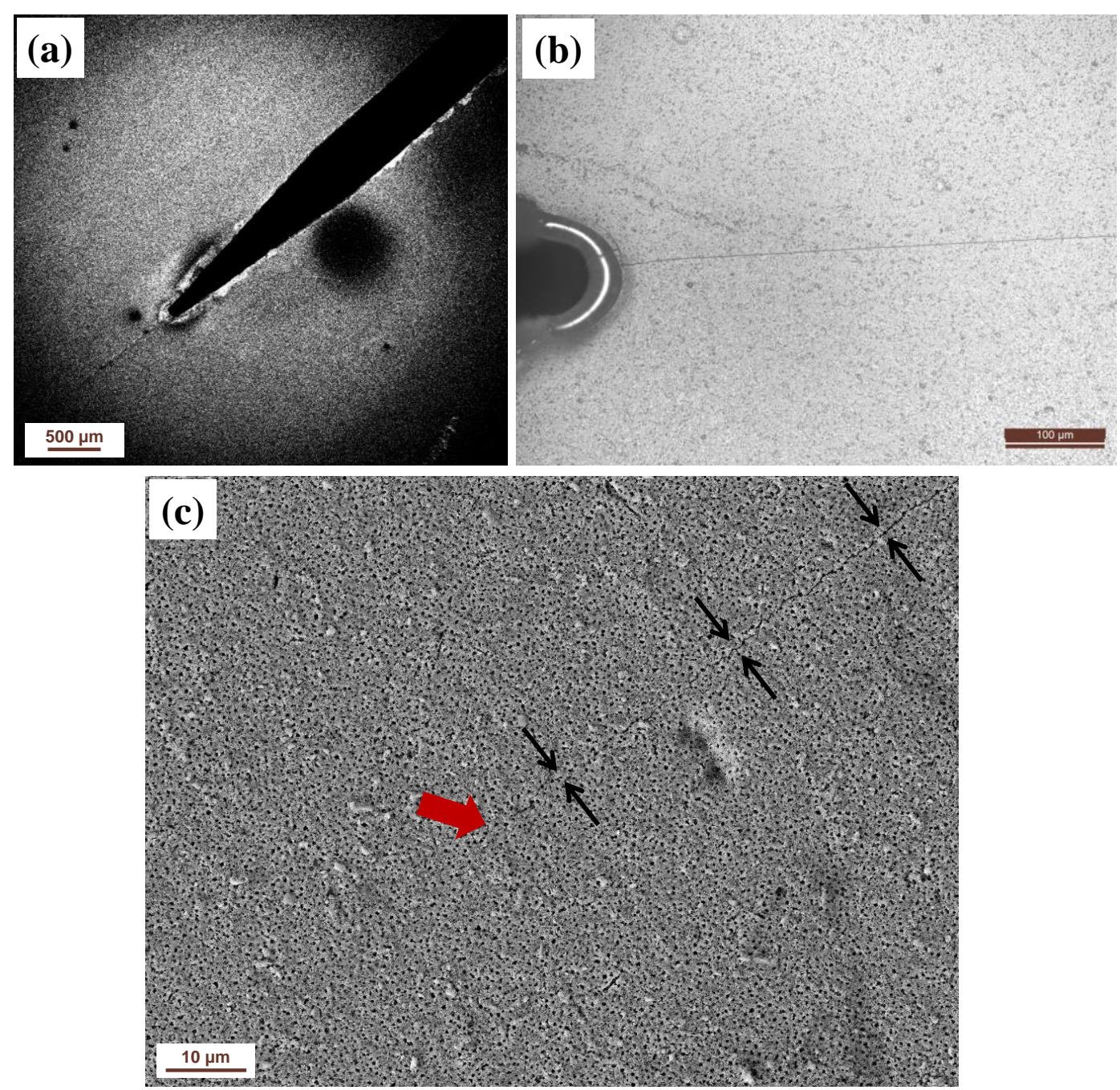

Figure 4: (a) SEM and (b) optical microscopy images of the notch tip and the propagated crack from the notch and (c) SEM image of the crack tip in the tested 3Y-TZP-25\%. The crack path and crack tip in (c) are shown by the black and red arrows, respectively.

\subsection{Compliance analysis}

Figure 5 shows the results of the compliance analysis for samples with different porosities. The samples vary not only with respect to porosity, but also (unintendedly) with respect to thickness. To exclude the effect of thickness, enabling a better comparison, the compliance values were multiplied by the cube of thickness $\left(C . t^{3}\right)$ in the plot versus the crack length (see Eqs. 5 and 6). As seen, variation of the compliance of all the porous 3Y-TZP samples with crack length in the investigated range (up to $30 \mathrm{~mm}$ ) can, to a very good approximation, be considered linear. In addition, clearly, the slope of the curves decreases by increasing sample porosity. 


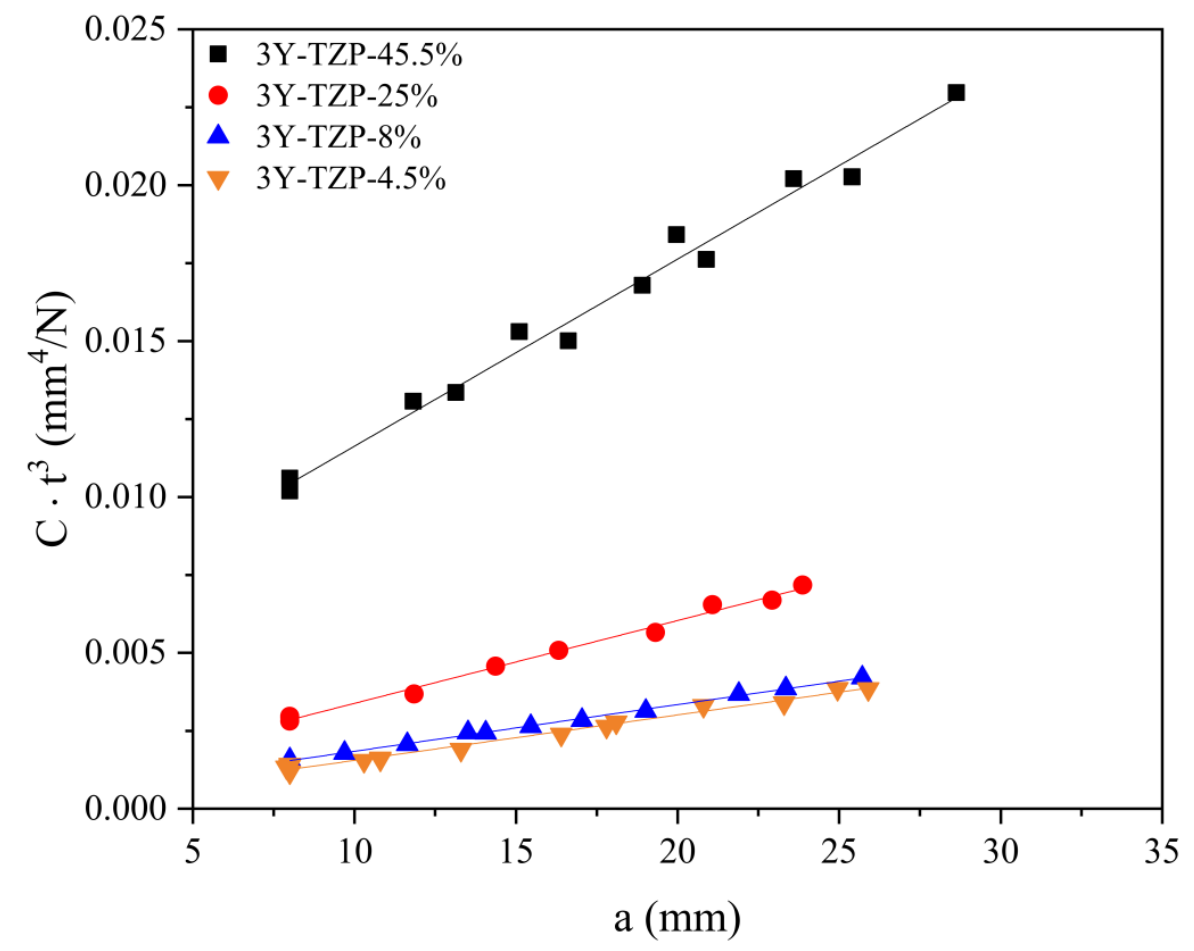

Figure 5: Compliance analysis of samples with different porosities; $a$ and $t$ refer to the crack length and samples thickness, respectively. The data at $a=8 \mathrm{~mm}$ correspond to the compliance analysis for the notch (i.e. before any crack growth).

The experimental $B$ and $D$ values (Eq. 5) calculated from the linear regression of the compliancecrack length data are presented in Table 2. The Young's modulus $(E)$ of the samples at different porosities (derived based on the Eq. 6) are compared with literature values of 3Y-TZP [34] and are in a good agreement with the previously reported values. Thus, the linear regression approach provides trustworthy results, although the sample geometry is complex.

Table 2: Results of the compliance analysis for samples with different porosities and dimensions.

\begin{tabular}{|c|c|c|c|c|}
\hline Sample name & $\begin{array}{c}\text { Experimental B } \\
{\left[\mathrm{N}^{-1}\right]}\end{array}$ & $\begin{array}{c}\text { Experimental D } \\
{[\mathrm{mm} / \mathrm{N}]}\end{array}$ & $\begin{array}{c}E(\mathrm{GPa}), \\
\text { this work }\end{array}$ & $\begin{array}{c}E(\mathrm{GPa}), \\
\text { from ref. [34] }\end{array}$ \\
\hline 3 Y-TZP-4.5\% & $8.2 \times 10^{-3}$ & $5.2 \times 10^{-3}$ & 189.4 & 189.9 \\
\hline 3 Y-TZP-8\% & $8.3 \times 10^{-3}$ & $1.93 \times 10^{-2}$ & 183.6 & 170.9 \\
\hline 3 Y-TZP-25\% & $2 \times 10^{-2}$ & $5.44 \times 10^{-2}$ & 101.2 & 102.5 \\
\hline 3 Y-TZP-45.5\% & $2.01 \times 10^{-2}$ & $1.89 \times 10^{-1}$ & 44.5 & 56.1 \\
\hline
\end{tabular}




\subsection{Fracture toughness and toughening effect}

Table 3 presents the fracture toughness of the 3Y-TZP samples. The apparent toughness of the samples, measured in ambient air with a displacement rate of $0.6 \mathrm{~mm} / \mathrm{min}$ is also provided in Table 3. It is clear that the stress corrosion caused by the air humidity has a significant effect on the measured toughness, as the toughness values in air are approximately 5-20\% lower than when measured in $\mathrm{N}_{2}$.

The toughness of 3YSZ-4.5\% is slightly lower than the value reported for a dense 3Y-TZP (6.1 MPa.m ${ }^{1 / 2}$ ) [11]. Also, the toughness of the samples with higher porosities is significantly lower. In addition to the effect of porosity, the lower fracture toughness could be a consequence of the very small grain sizes of the studied samples that reduce the tendency of the tetragonal grains to transform to the monoclinic phase hence decrease the effect of phase transformation toughening.

Table 3: Fracture toughness (measured in $N_{2}$ using a displacement rate of $6 \mathrm{~mm} / \mathrm{min}$ ), apparent toughness (measured in ambient air with a displacement rate of $0.6 \mathrm{~mm} / \mathrm{min}$ ) and slow crack growth parameters of the samples at different porosities. All the measurements except the high temperature fracture toughness reported for $3 Y-T Z P-8 \%$ are done at room temperature. The numbers in parentheses show the standard deviation

\begin{tabular}{|c|c|c|c|c|}
\hline \multirow{2}{*}{ Sample name } & $\begin{array}{c}\text { Fracture toughness } \\
\left(\mathrm{MPa} . \mathrm{m}^{1 / 2}\right)\end{array}$ & $\begin{array}{c}\text { Apparent toughness } \\
\left(\mathrm{MPa} . \mathrm{m}^{1 / 2}\right)\end{array}$ & \multicolumn{2}{|c|}{$\begin{array}{c}\text { Slow crack growth } \\
\text { parameters }\end{array}$} \\
\cline { 3 - 5 } & $4.27(0.06)$ & $3.94(0.10)$ & $42.3(1.9)$ & $7.8 \times 10^{-28}$ \\
\hline $3 \mathrm{Y}-\mathrm{TZP}-4.5 \%$ & $3.95(0.12)$ & $3.74(0.02)$ & $33.9(2)$ & $5.2 \times 10^{-23}$ \\
\hline $3 \mathrm{Y}-\mathrm{TZP}-\mathrm{TZP} \%$ & {$\left[1.62(0.05)\right.$ at $\left.800^{\circ} \mathrm{C}\right]$} & $1.68(0.06)$ & $46.3(1.7)$ & $3.8 \times 10^{-15}$ \\
\hline $3 \mathrm{Y}-\mathrm{TZP}-45.5 \%$ & $1.93(0.15)$ & $0.58(0.06)$ & $35.6(2.5)$ & $2 \times 10^{5}$ \\
\hline
\end{tabular}

In a tetragonal zirconia ceramic, the transformation toughening mechanism is facilitated if the size of grains is close to the critical grain size for the tetragonal to monoclinic phase transformation. If the grains are much smaller than this critical grain size, the tetragonal phase is over-stabilized, i.e. it does not have the potential to transform to the monoclinic phase upon an applied stress. For a dense $3 \mathrm{Y}-\mathrm{TZP}$, the critical grain size for the tetragonal to monoclinic phase transformation is approximately 1 micron [35] (though higher values have also been reported [36]). The effectiveness of transformation toughening in 3Y-TZP ceramics having grain size below approximately $300 \mathrm{~nm}$ has been questioned in literature [36,37]. The average grain size of the samples studied in this work varies from $40-238 \mathrm{~nm}$. It is thus questionable if there is any phase transformation toughening in the tested samples.

Raman spectroscopy analysis of the samples studied in the current work (at different porosities) showed no monoclinic phase on the fractured surfaces. A similar observation is also reported by Theunissen and co-workers [38], where no monoclinic phase could be detected in the fractured surfaces of $2.5 \mathrm{YSZ}$ samples with grain sizes of 180 and $300 \mathrm{~nm}$. This might suggest that the 
transformation toughening mechanism is not effective in the samples studied in this work. However, the measured values of toughness are significantly higher than 8YSZ cubic zirconia samples reported in literature, where no transformation toughening effect is present. For instance, fracture toughness of 8 YSZ ceramics having pure cubic phase, $97.6 \%$ of the theoretical density and average grain size of $295 \mathrm{~nm}$ is reported to be $3.16 \mathrm{MPa}^{1 / 2}$ [39]. Nevertheless, the 3 Y-TZP-8\% has $25 \%$ higher fracture toughness (3.95 MPa.m ${ }^{1 / 2}$ ), despite its higher porosity. Furthermore, the fracture toughness of $3 \mathrm{Y}-\mathrm{TZP}-8 \%$ at $800^{\circ} \mathrm{C}$ was measured to be $1.62 \mathrm{MPa}^{1 / 2}$ (see Table 3 ); this is approximately $60 \%$ lower than the room temperature value $\left(3.95 \mathrm{MPa} \cdot \mathrm{m}^{1 / 2}\right)$. The high fracture toughness in the porous $3 \mathrm{Y}$-TZP samples is unlikely to be a consequence of ferroelastic domain switching, as this toughening mechanism has not been reported in fine grained TZP ceramics [40,41]. In addition, ferroelastic toughening is temperature invariant [42], so its effect should not decrease at $800^{\circ} \mathrm{C}$, in contrast to the toughness results obtained in this work.

The increased fracture toughness compared to the cubic 8YSZ sample as well as the observed decrease in toughness with increasing temperature, which is a typical characteristic of the transformation toughening mechanism [43], therefore suggests that there is some transformation toughening even in the fine grained samples studied here. Note, the tetragonal to monoclinic phase transformation zone in a tetragonal zirconia ceramic under fracturing can be very small. For instance, Zhang and co-workers [44] have observed this transformation zone in 3Y-TZP with average grain size of around $300 \mathrm{~nm}$ to be 1 micron. This very small transformation zone can therefore make it difficult to detect any monoclinic phase using Raman spectroscopy in the fractured surfaces of porous, fine grained ceramics studied in this work.

Increasing porosity will usually lower the critical grain size due to the lower levels of strain energy. Furthermore, in a porous material the tetragonal grains can more easily undergo the stress induced transformation resulting from the lower stiffness of the neighboring matrix [45]. Thus, the tetragonal to monoclinic phase transformation may take place for smaller grain sizes in a porous material compared to a dense one, as is hypothesized in the present work. Nevertheless, detailed crystalline phase analysis of the fractured surfaces would be required to confirm this hypothesis.

\subsection{Slow crack growth behavior}

Figure 6 shows typical load relaxation curves for the studied samples. Having very thin and porous specimens, the measurements entailed working at small loads (in the range of $\approx 0.4-2.5 \mathrm{~N}$ ) and monitoring very small load drops $(\approx 0.1-0.7 \mathrm{~N})$ under the relaxation. The low noise level compared to the systematic variations indicates that the measurements can be considered reliable. 


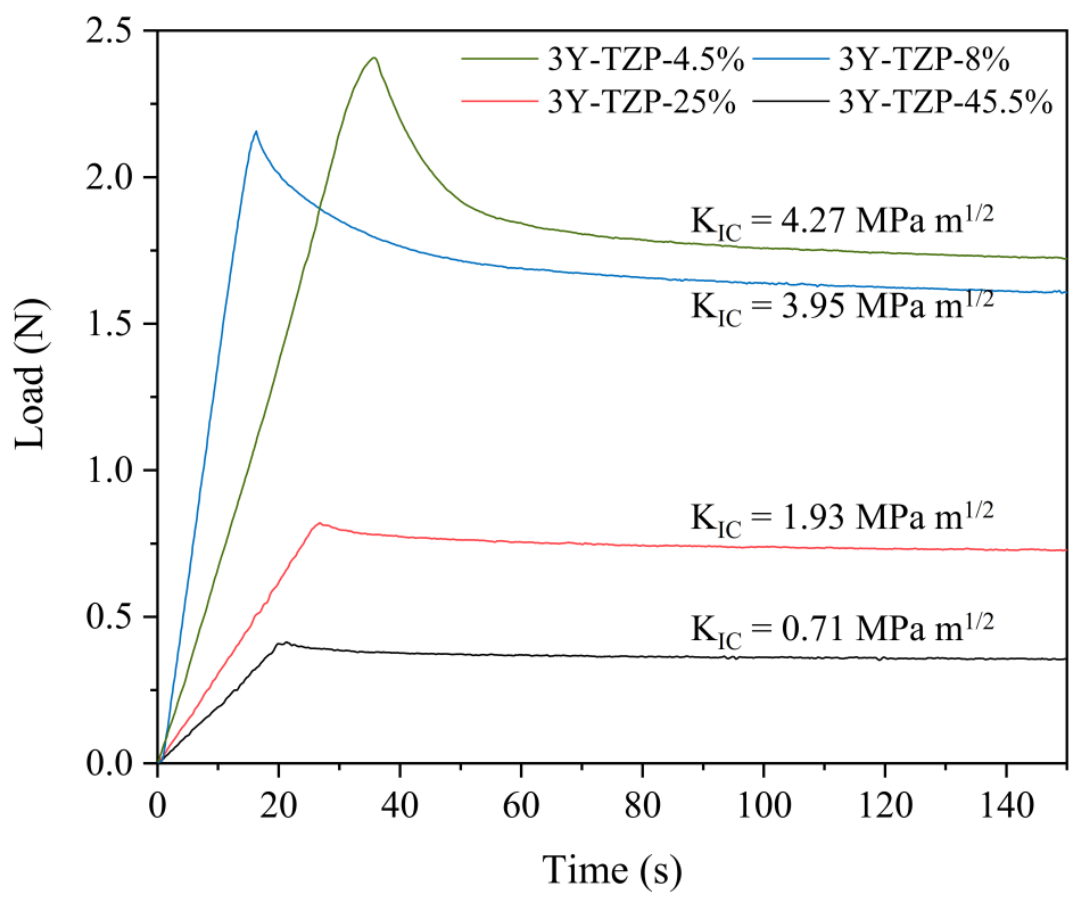

Figure 6: Typical load relaxation curves obtained in this work.

Figure 7 shows the $V$ - $K_{I}$ curves obtained from the successive relaxation tests for samples with different porosities. For each porosity, the successive relaxation tests were carried out on the same sample. For the 3Y-TZP-4.5\% and 3Y-TZP-8\%, a clear shift to lower intensity factors and higher crack velocities is observed. This indicates a clear dependency of the stress intensity factor on the crack length in the test, even with the very thin samples studied ( $t: \mathrm{W}: \mathrm{L} \approx 1: 75: 130)$. The disparity between the two $V$ - $K_{I}$ curves reduces for the samples with higher porosities, i.e. 3Y-TZP-25\% and $3 \mathrm{Y}-\mathrm{TZP}-45 \%$.

The geometry of the samples investigated in this work is very different from those studied by Ciccotti and co-workers [23,24]. Applying the Ciccotti's correction would thus require extrapolation to very long ranges, which is not recommended by the authors. Here, we followed the strategy proposed by Chevalier et al. [20] and considered variation of $K_{I}$ versus $a$ given by Eq. 2, but with an experimental re-evaluation of the $\gamma$ component. The corrected $V-K_{I}$ curves are accordingly presented in Figure 7. For each porosity, an exponent providing the best result in reunifying the different curves was determined. The $\gamma$ exponent for 3Y-TZP-4.5\%, 3Y-TZP-8\%, 3Y-TZP-25\% and 3Y-TZP-45.5\% was calculated to be $0.22,0.21,0.1$ and 0.08 , respectively. As seen, the empirical correction primarily obtained for samples with dimensions of $\mathrm{t}: \mathrm{W}: \mathrm{L} \approx 1: 10: 20$ [20] can be applied for the porous samples studied in this work, after a modification in the value of exponent. That is, by increasing porosity, a lower exponent value is required for the reproducibility of successive $V$ - $K_{I}$ curves.

To explain the change of stress intensity factor in samples with different porosities, the crack length in the tensile and compressive sides of the 3YSZ-4.5\% and 3YSZ-25\% was accurately measured using SEM. The difference in crack length for the 3 YSZ-4.5\% was $1.94 \mathrm{~mm}$, while the corresponding value in the $3 \mathrm{YSZ}-25 \%$ was $0.23 \mathrm{~mm}$. This means a lower curvature of crack front (see Figure 2) in the sample at higher porosity. 

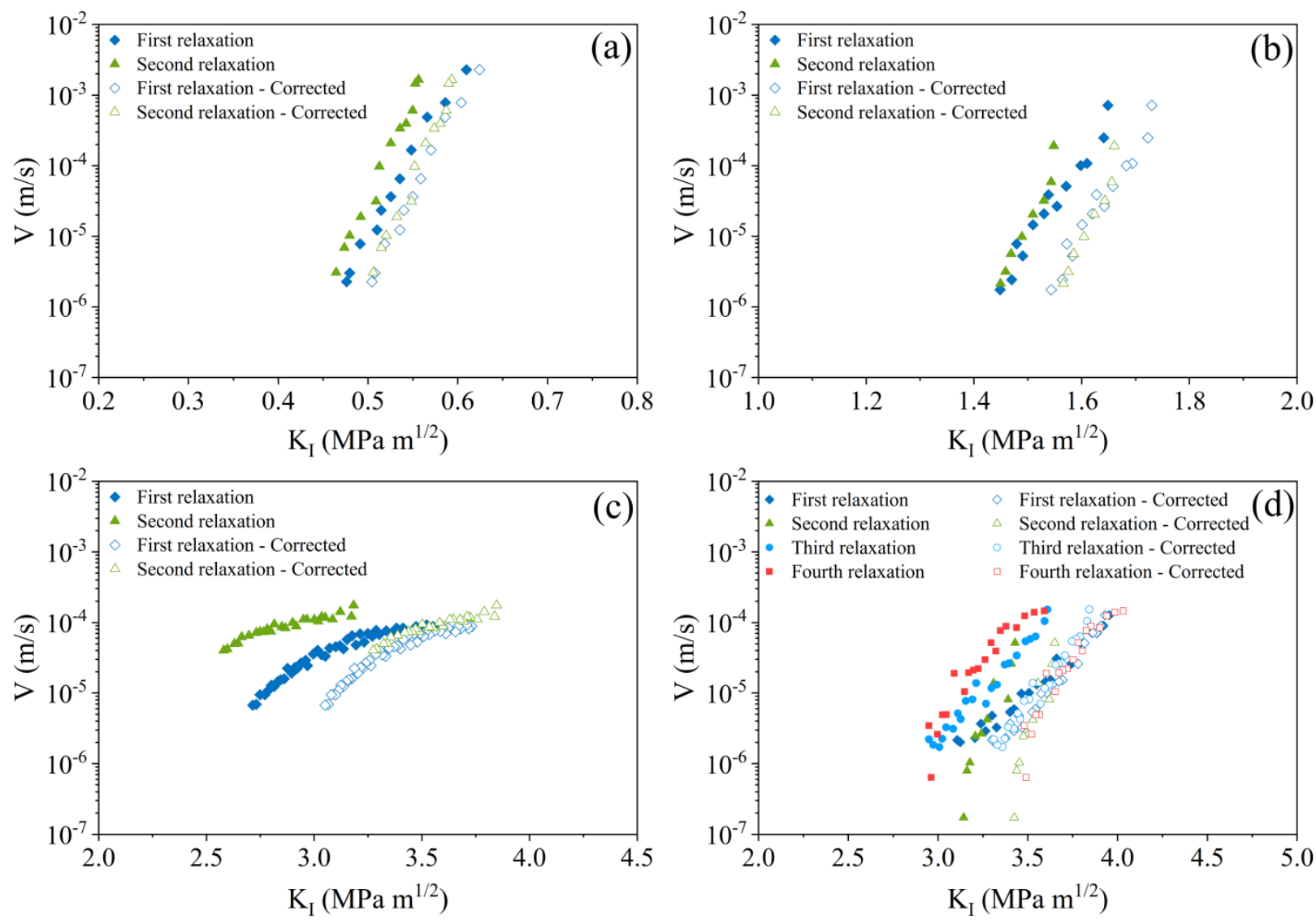

Figure 7: V-KI curves for successive relaxation tests in (a) 3Y-TZP-45.5\%, (b) 3Y-TZP-25\%, (c) 3Y-TZP-8\% and (d) $3 Y-T Z P-4.5 \%$, without (solid symbols) and with (open symbols) correction.

As discussed by Chevalier and co-workers [20] the dependency of stress intensity factor on crack length cannot be due to the change of crack surface area as the crack propagates, neither can it be explained by the corrections considering the effect of curved crack front on crack velocity. However, the buildup of differences in crack length on the tensile and compressive sides, that leave relatively more and more unbroken ligaments on the latter, is a plausible explanation to account for the dependency of the stress intensity factor on crack length. Our work supports this hypothesis; we see a lower dependency of the stress intensity factor with crack length for samples with high porosity, i.e. samples that display smaller differences in crack length, than samples with low porosity. This decreased dependency manifests itself as a lower coefficient in Eq. 2.

$V$ - $K_{I}$ curves for samples with different porosities, calculated using the above-obtained correction coefficients, are shown in Figure 8. The typical three-stages SCG behavior of zirconia ceramics in air is distinguishable in the $V-K_{I}$ curve of the $3 \mathrm{Y}-\mathrm{TZP}-4.5 \%$. The second stage occurs at a crack velocity of approximately $5 \times 10^{-4} \mathrm{~m} / \mathrm{s}$. $3 \mathrm{Y}-\mathrm{TZP}-8 \%$ also shows the three typical stages but with a very narrow second stage. For 3Y-TZP-25\% and 3Y-TZP-45.5\% samples, only one stage is seen in the crack velocity range of $10^{-6}-10^{-3} \mathrm{~m} / \mathrm{s}$. 


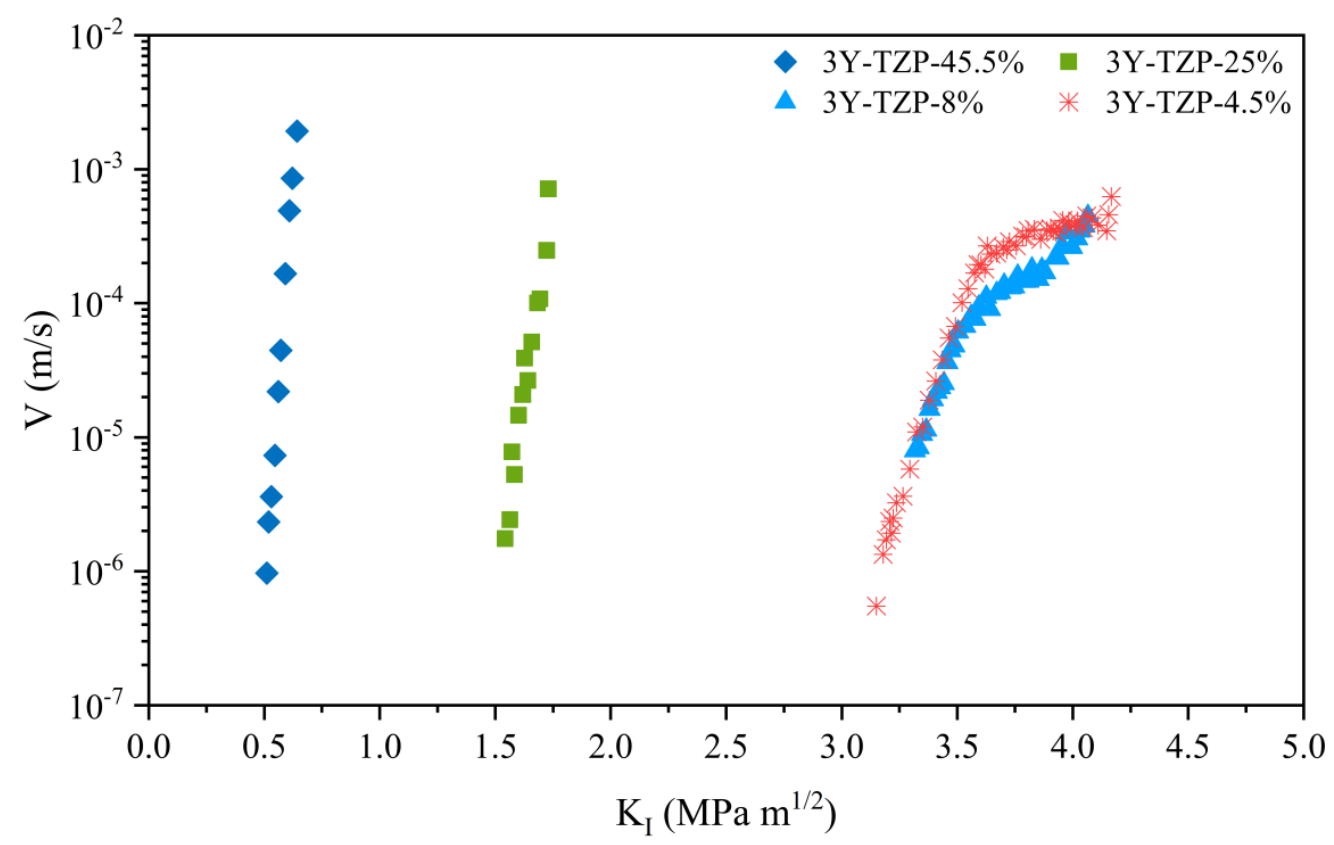

Figure 8: V-KI curves for the samples having different porosities.

Crack propagation in the first stage of the $V$ - $K_{I}$ diagram (curve $a$, Figure 1) is basically controlled by the rate of reaction between the corrosive molecules and chemical bonds of the ceramic at cracks tips. This stage is highly affected by the chemical concentration, temperature and applied stress. Stage II, corresponds to the state where the crack growth is controlled by diffusion of corrosive species to the crack tip. Here, the crack velocity is basically constant. Stage II connects stage I to the stage III, where the crack velocity increases rapidly with the applied stress. The crack propagation rate in the third stage is usually higher than the transport rate of corrosive species to the crack tip. Consequently, the separation of crack surfaces happens without a necessary interaction of reactive species with ceramic bonds. This is similar to the crack propagation without the presence of corrosive species, such that stage III can be approximately corresponded to the fast fracture $\left(K_{I}=K_{I C}\right)[15,16]$.

Although the SCG experiments in the present study are only carried out in laboratory air, assuming that the stress-corrosion is caused by water molecules present in air is realistic, as the waterassisted crack propagation in zirconia has well been reported in literature [9-12]. Chevalier and coworkers [11] reported the slow crack growth behavior of dense 3Y-TZP in ambient air and water. In air, the typical trimodal behavior was observed, and the second stage occurred at the crack velocities of around $10^{-4} \mathrm{~m} / \mathrm{s}$. In water, however, only one stage was seen, with a slope close to the slope of the first stage obtained in ambient air. The reason can be explained considering that the transfer of water molecules to the crack tip is increased at higher concentration, indicating that the water molecules can interact with the crack tip even at higher crack propagation rates. Accordingly, the second stage shifts to higher crack velocities, as seen in Figure 1. In liquid water, in particular, the water molecules can diffuse and interact with the ceramic bonds even at high crack velocities.

In this work, we evidence a clear role of the porosity on the features of the $V$ - $K_{I}$ curves, which can be explained on the basis of the ability of water molecules to access the crack tip. In the 3Y-TZP$4.5 \%$ and $3 \mathrm{Y}-\mathrm{TZP}-8 \%$, the second stage occurred at higher crack velocities than previously reported for dense samples $\left(10^{-4} \mathrm{~m} / \mathrm{s}\right.$, reported for example in [11] and [44]), as water molecules have easier access to the adsorption sites at the crack tip because of residual porosity. In 3Y-TZP-25\% and 3Y- 
TZP45\%, only one stage was observed, due to the highly connected porosity of the materials, providing a full percolation (the corrosive species can always reach the crack tip, without any crack rate limitation even in air).

The slow crack growth parameters ( $n$ and $A$ ) were determined for the first stage of the $V$ - $K_{I}$ curves of $3 \mathrm{Y}-\mathrm{TZP}-4.5 \%$ and $3 \mathrm{Y}-\mathrm{TZP}-8 \%$ and the entire $V-K_{I}$ curves of $3 \mathrm{Y}-\mathrm{TZP}-25 \%$ and $3 \mathrm{Y}-\mathrm{TZP}-$ $45.5 \%$. The results are presented in Table 3.

The fracture thresholds, $K_{I 0}$, for 3 Y-TZP samples were estimated by extrapolating the first stage of the corresponding $V-K_{I}$ curves to the crack velocity of $10^{-11} \mathrm{~m} / \mathrm{s}$. Figure 9 presents the estimated fracture threshold together with toughness of the samples at different porosities. The ratio of fracture threshold to fracture toughness $\left(K_{I O} / K_{I C}\right)$ of the samples at different porosities is also presented in Figure 9.

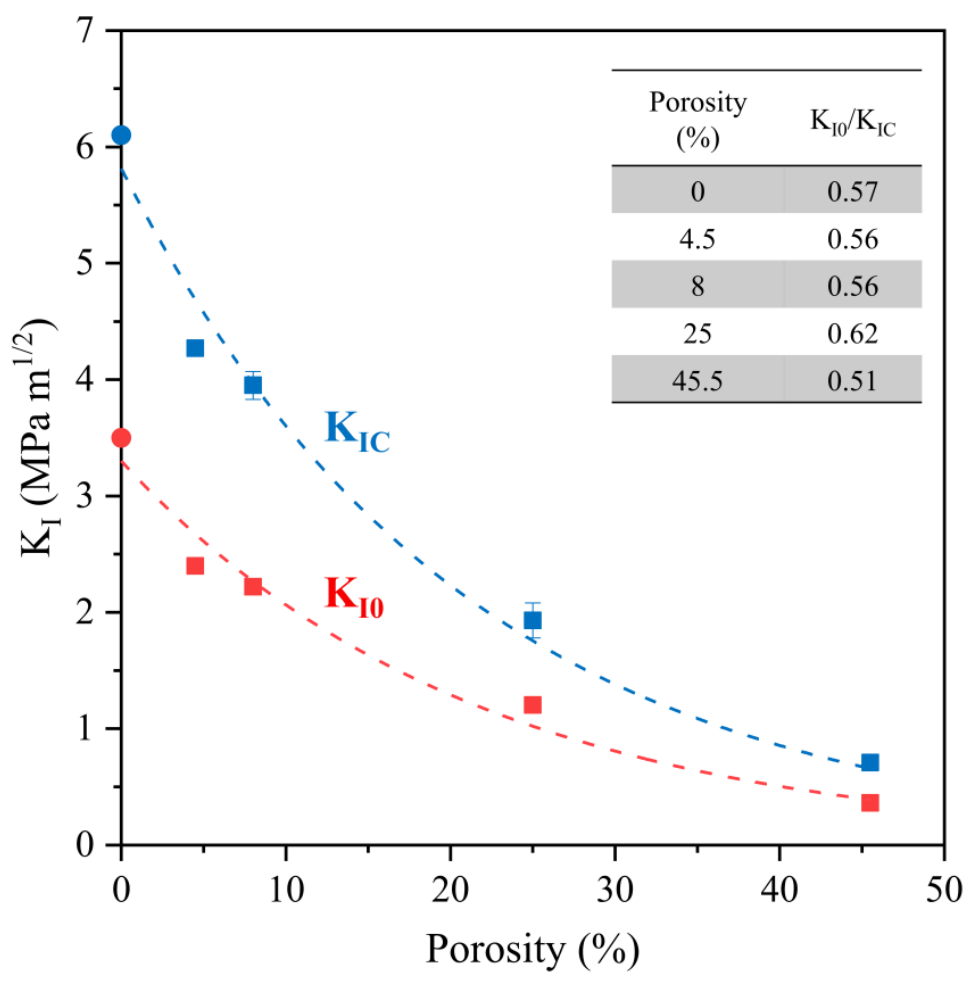

Figure 9: Fracture toughness and threshold of 3Y-TZP samples as a function of porosity, (-) obtained in the current work and $(\bullet)$ reported by Chevalier and co-workers [11].

As seen, $K_{I O} / K_{I C}$ ratio for all samples is found to be around $0.56 \pm 0.06$. The crack growth in the samples can therefore occur at stresses as low as $50 \%$ of the fracture stress.

The relatively similar $K_{I 0} / K_{I C}$ ratio for samples at different porosities can be explained considering the basic Griffith criterion for brittle fracture [46]: The critical stress for fracture in a brittle material $\left(\sigma_{c}\right)$ is proportional to:

$$
\sigma_{c} \propto \sqrt{E \gamma}
$$

where $E$ is the Young's modulus of the material, and $\gamma$ is the surface energy. 
In fact, the intrinsic surface energy of a given material is specified considering a fracturing in vacuum, corresponding to the fracture toughness of the material. In a corrosive atmosphere, the surface energy decreases resulting from the interaction of corrosive molecules with the material at the crack tip; the reason why under SCG condition the material can fail at stress intensity factors below its fracture toughness $[6,16]$. Consequently, the $K_{I 0} / K_{I C}$ ratio is correlated to the difference in surface energy under vacuum and in a reactive environment, and hence it should be independent of the porosity of the material.

From Figure 9, it is seen that at porosities above $\approx 25 \%$, which is the range of interest for many energy applications of the material, the $K_{I 0}$ drops to very low values, well below $1.5 \mathrm{MPa} . \mathrm{m}^{1 / 2}$. These significantly low ranges of fracture thresholds thus need to be considered when designing thin and porous zirconia based ceramics for energy devices, to fulfill their long term mechanical reliability.

\section{Conclusions}

In this work, the slow crack growth behavior of thin $(\sim 0.25 \mathrm{~mm})$, porous 3 Y-TZP samples, having a porosity in the range from 4.5 to $45.5 \%$, were studied. The fracture toughness, fracture threshold and slow crack growth parameters of the samples were determined, highlighting:

- The compliance of the specimens was concluded to be a linear function of crack length. Previous analyses of the double torsion specimen could be applied here, with some calibration on the $K_{I}$ versus crack length equations. The $K_{I}(a)$ dependency decreased with increasing the porosity of samples. This was explained by the lower extent of unbroken ligaments in samples at higher porosities.

- The $V-K_{I}$ curves of the sample with the lowest porosity exhibited the typical trimodal SCG behavior, as shown in previous works for dense 3Y-TZP. As porosity increased, the length of the second stage decreased. In samples with $25 \%$ porosity and higher, only one stage was observed, because of the easier access of water molecules to the crack tip.

- No monoclinic phase could be detected on the fractured surfaces of the samples. However, some transformation toughening was hypothesized to take place to account for the results even in the fine grained samples studied.

- The $K_{I O} / K_{I C}$ ratio for porous 3Y-TZP samples was determined to be consistent with previous works on dense materials, with a value of $0.56 \pm 0.06$.

- The SCG experiments in the present study were conducted in ambient air and at room temperature. The results can well be applied when e.g. the handling, storage or room temperature use of the components are concerned. However, a full picture of the SCG behavior of the materials is drawn when the phenomenon is also studied under other relevant conditions of use for a given application. For instance, for SOCs applications the SCG studies at $800^{\circ} \mathrm{C}$ (i.e. the typical operating temperature of the cells) would add complementary information and should also be considered.

\section{Acknowledgement}

The authors would like to thank Innovation Fund, Denmark, for providing funding for this research under the framework of SYNFUEL (sustainable synthetic fuels from biomass gasification and electrolysis) project (File No. 4106-00006B). 


\section{References}

[1] T. Klemensø, D. Boccaccini, K. Brodersen, H.L. Frandsen, P. V. Hendriksen, Development of a novel ceramic support layer for planar solid oxide cells, Fuel Cells. 14 (2014) 153-161.

[2] G. Li, H. Qi, Y. Fan, N. Xu, Toughening macroporous alumina membrane supports with YSZ powders, Ceram. Int. 35 (2009) 1641-1646.

[3] A. Atkinson, A. Selçuk, Mechanical behaviour of ceramic oxygen ion-conducting membranes, Solid State Ionics. 134 (2000) 59-66.

[4] J. Chevalier, L. Gremillard, A. V. Virkar, D.R. Clarke, The tetragonal-monoclinic transformation in zirconia: Lessons learned and future trends, J. Am. Ceram. Soc. 92 (2009) 1901-1920.

[5] J. Chevalier, S. Deville, G. Fantozzi, J.F. Bartolomé, C. Pecharroman, J.S. Moya, L.A. Diaz, R. Torrecillas, Nanostructured ceramic oxides with a slow crack growth resistance close to covalent materials, Nano Lett. 5 (2005) 1297-1301.

[6] C. Olagnon, J. Chevalier, V. Pauchard, Global description of crack propagation in ceramics, J. Eur. Ceram. Soc. 26 (2006) 3051-3059.

[7] T.T. Molla, K. Kwok, H.L. Frandsen, Modeling the Mechanical Integrity of Generic Solid Oxide Cell Stack Designs Exposed to Long-term Operation, Fuel Cells. 19 (2019) 96-109.

[8] A.H. De Aza, J. Chevalier, G. Fantozzi, M. Schehl, R. Torrecillas, Crack growth resistance of alumina, zirconia, and zirconia toughened alumina ceramics for joint prostheses, Key Eng. Mater. 23 (2002) 937-945.

[9] F. Zhang, J. Chevalier, C. Olagnon, B. Van Meerbeek, J. Vleugels, Slow crack growth and hydrothermal aging stability of an alumina-toughened zirconia composite made from $\mathrm{La}_{2} \mathrm{O}_{3}-$ doped 2Y-TZP, J. Eur. Ceram. Soc. 37 (2017) 1865-1871.

[10] R. Benzaid, J. Chevalier, M. Saâdaoui, G. Fantozzi, M. Nawa, L.A. Diaz, R. Torrecillas, Fracture toughness, strength and slow crack growth in a ceria stabilized zirconia-alumina nanocomposite for medical applications, Biomaterials. 29 (2008) 3636-3641.

[11] J. Chevalier, C. Olagnon, G. Fantozzi, Subcritical Crack Propagation in 3Y-TZP Ceramics: Static and Cyclic Fatigue, J. Am. Ceram. Soc. 82 (1999) 3129-3138.

[12] L. Gremillard, J. Chevalier, T. Epicier, G. Fantozzi, Improving the Durability of a BiomedicalGrade Zirconia Ceramic by the Addition of Silica, J. Am. Ceram. Soc. 85 (2002) 401-7.

[13] D.N. Boccaccini, H.L. Frandsen, S. Soprani, M. Cannio, T. Klemensø, V. Gil, P.V. Hendriksen, Influence of porosity on mechanical properties of tetragonal stabilized zirconia, J. Eur. Ceram. Soc. 38 (2018) 1720-1735.

[14] M. Radovic, E. Lara-Curzio, G. Nelson, Fracture Toughness and Slow Crack Growth Behavior of Ni-YSZ and YSZ as a Function of Porosity and Temperature, in: Adv. Solid Oxide Fuel Cells II Ceram. Eng. Sci. Proc., 2008: pp. 373-381.

[15] S.W. Freiman, Effect of chemical enviroments on slow crack growth in glasses and ceramics, J. Geophys. Res. 89 (1984) 4072.

[16] B. Lawn, Chemical processes in crack propagation: kinetic fracture, in: Fract. Brittle Solids, 2nd ed., Cambridge: Cambridge University Press, 1993: pp. 106-142.

[17] A.G. Evans, A method for evaluating the time-dependent failure characteristics of brittle 
materials - and its application to polycristalline alumina, J. Mater. Sci. 7 (1972) 1137-1146.

[18] D. p. Williams, A. g. Evans, A Simple Method for Studying Slow Crack Growth, J. Test. Eval. 1 (1973) 264-270.

[19] M.K. FERBER, S.D. Brown, Subcritical Crack Growth in Dense Alumina Exposed to Physiological Media, J. Am. Ceram. Soc. 63 (1980) 424-429.

[20] J. Chevalier, M. Saadaoui, C. Olagnon, G. Fantozzi, Double-torsion testing a 3Y-TZP ceramic, Ceram. Int. 22 (1996) 171-177.

[21] M.E. Ebrahimi, J. Chevalier, G. Fantozzi, Slow crack-growth behavior of alumina ceramics, J. Mater. Res. 15 (2000) 142-147.

[22] A. Shyam, E. Lara-Curzio, The double-torsion testing technique for determination of fracture toughness and slow crack growth behavior of materials: A review, J. Mater. Sci. 41 (2006) 4093-4104.

[23] M. Ciccotti, Realistic Finite-Element Model for the Double-Torsion Loading Configuration, J. Am. Ceram. Soc. 83 (2000) 2737-2744.

[24] M. Ciccotti, G. Gonzato, F. Mulargia, The double torsion loading configuration for fracture propagation: An improved methodology for the load-relaxation at constant displacement, Int. J. Rock Mech. Min. Sci. 37 (2000) 1103-1113.

[25] T.H. Becker, T.J. Marrow, R.B. Tait, An Evaluation of the Double Torsion Technique, Exp. Mech. 51 (2011) 1511-1526.

[26] M.A. Madjoubi, M. Hamidouche, N. Bouaouadja, J. Chevalier, G. Fantozzi, Experimental evaluation of the double torsion analysis on soda-lime glass, J. Mater. Sci. 42 (2007) 7872 7881.

[27] J.A. Escribano, J. García-Fayos, J.M. Serra, Shaping of 3YSZ porous substrates for oxygen separation membranes, J. Eur. Ceram. Soc. 37 (2017) 5223-5231.

[28] S. Ramousse, M. Menon, K. Brodersen, J. Knudsen, U. Rahbek, P.H. Larsen, Manufacturing of Anode-Supported SOFC's: Processing Parameters and their Influence, ECS Trans. S. 7 (2007) 317-327.

[29] M. Pihlatie, A. Kaiser, P.H. Larsen, M. Mogensen, Dimensional behaviour of Ni-YSZ anode supports for SOFC under RedOx cycling conditions, ECS Trans. 7 (2007) 1501-1510.

[30] E.R. Fuller Jr., An Evaluation of Double-Torsion Testing - Analysis, 1979.

[31] R.L. Coble, Sintering crystalline solids. I. intermediate and final state diffusion models, J. Appl. Phys. 32 (1961) 787-792.

[32] S. Liu, I. Chen, Fatigue of Yttria-Stabilized Zirconia: I, Fatigue Damage, Fracture Origins, and Lifetime Prediction, J. Am. Ceram. Soc. 74 (1991) 1197-1205.

[33] G.W. Dransmann, R.W. Steinbrech, A. Pajares, F. Guiberteau, A. Dominguez-Rodriguez, A.H. Heuer, Indentation Studies on $\mathrm{Y}_{2} \mathrm{O}_{3}$-Stabilized $\mathrm{ZrO}_{2}$ : II, Toughness Determination from Stable Growth of Indentation-Induced Cracks, J. Am. Ceram. Soc. 77 (1994) 1194-1201.

[34] A. Selçuk, A. Atkinson, Elastic properties of ceramic oxides used in solid oxide fuel cells (SOFC), J. Eur. Ceram. Soc. 17 (1997) 1523-1532.

[35] F.F. Lange, Transformation toughening - Part 3 Experimental observations in the $\mathrm{ZrO}_{2}-\mathrm{Y}_{2} \mathrm{O}_{3}$ 
system, J. Mater. Sci. 17 (1982) 240-246.

[36] M. Trunec, Effect of grain size on mechanical properties of 3Y-TZP ceramics, Ceram. Silikaty. 52 (2008) 165-171.

[37] J. Eichler, J. Rödel, U. Eisele, M. Hoffman, Effect of grain size on mechanical properties of submicrometer 3Y-TZP: Fracture strength and hydrothermal degradation, J. Am. Ceram. Soc. 90 (2007) 2830-2836.

[38] G.S.A.M. Theunissen, J.S. Bouma, a. J. a. Winnubst, a. J. Burggraaf, Mechanical properties of ultra-fine grained zirconia ceramics, J. Mater. Sci. 27 (1992) 4429-4438.

[39] M. Mazaheri, M. Valefi, Z.R. Hesabi, S.K. Sadrnezhaad, Two-step sintering of nanocrystalline $8 \mathrm{Y}_{2} \mathrm{O}_{3}$ stabilized $\mathrm{ZrO}_{2}$ synthesized by glycine nitrate process, Ceram. Int. 35 (2009) 13-20.

[40] G.S. a. M. Theunissen, J.S. Bouma, a. J. a. Winnubst, a. J. Burggraaf, Mechanical properties of ultra-fine grained zirconia ceramics, J. Mater. Sci. 27 (1992) 4429-4438.

[41] A. Dash, B.N. Kim, J. Klimke, J. Vleugels, Transparent tetragonal-cubic zirconia composite ceramics densified by spark plasma sintering and hot isostatic pressing, J. Eur. Ceram. Soc. 39 (2019) 1428-1435.

[42] A. V. Virkar, R.L.K. Matsumoto, Ferroelastic Domain Switching as a Toughening Mechanism in Tetragonal Zirconia, J. Am. Ceram. Soc. 69 (1986) C224-C226.

[43] R.H.J. Hannink, P.M. Kelly, B.C. Muddle, Transformation Toughening in ZirconiaContaining Ceramics, J. Am. Ceram. Soc. 83 (2004) 461-487.

[44] F. Zhang, H. Reveron, B.C. Spies, B. Van Meerbeek, J. Chevalier, Trade-off between fracture resistance and translucency of zirconia and lithium-disilicate glass ceramics for monolithic restorations, Acta Biomater. 91 (2019) 24-34.

[45] F.F. Lange, Transformation toughening-Part 3 Experimental observations in the $\mathrm{ZrO}_{2}-\mathrm{Y}_{2} \mathrm{O}_{3}$ system, J. Mater. Sci. 17 (1982) 240-246.

[46] A.A. Griffith, VI. The phenomena of rupture and flow in solids, Philos. Trans. R. Soc. London. Ser. A,. 221 (1921) 163-198. 